\title{
ARCHITECTURE, ART, AND MODERATE MORALISM
}

\section{Noël Carroll}

\begin{abstract}
In this essay Noël Carroll explores the question of whether a moral defect in a work of architectural art can ever also count as an aesthetic /artistic defect. Adopting the stance of a moderate moralist and mobilizing what has been called the "uptake argument," he argues against the moderate autonomist that sometimes a moral defect in an architectural artwork can also be an aesthetic/artistic defect.
\end{abstract}

\section{KEYWORDS}

Vitruvius, R. Venturi, Moderate autonomism, Moderate moralism, The aesthetic theory of art, The uptake argument

Architecture is obviously connected to ethics in a multitude of ways. Some include: that buildings must possess what Vitruvius called firmitas - solidity, firmness or solidity ${ }^{1}$ - lest they will collapse and kill their inhabitants or, at least, injure them; that buildings must be made honestly - the builder must not cheat his/her clients by employing cheaper materials than the contract calls for; the architect should treat his workers fairly - he/she should not endanger their lives, should pay them a living wage, not employ slave labor etc.; the architect should not design unhealthy spaces and, in general, should not be complicit in immoral projects. These are all negative moral obligations. But architecture is also beholden to ethics by way of promoting the good. Architects should do no harm. But they should also contribute to better living.

Nevertheless, it would appear that the architect can meet all these negative obligations and provide benefits as well solely by way of material construction and respect for the ethical norms governing material construction. In other words, the aforesaid ethical concerns can be met by building pure and simple. They do not appear to require the exercise of architecture as a fine art - that is, architecture as a practice with an aesthetic dimension.

Vitruvius defined architecture as having the properties of firmitas (solidity), utilitas (function or use) and venustas (the properties of Venus, like beauty, grace or, as currently interpreted, appearance 
or looks - as in "good" looks). ${ }^{2}$ As we have seen firmitas has a straightforward connection to ethics. Likewise, utilitas is related to ethics insofar as those functions should be at least not evil and, it is to be hoped, sometimes conducive to social goodness. But what about venustas? What connection, if any, does it have to ethics? That is the question of what relation, if any, does architectural aesthetics or architecture-as-a-fine-art have to morality.

Throughout history in the West, at least up until the eighteenth century, architecture maintained a lofty status in the hierarchy of the arts. The pyramids, the Parthenon, the Colosseum, Roman roads and aqueducts were wonders of the ancient world, while the cathedrals of the Middle Ages were probably the greatest artistic achievements of those times in Europe, only to be outshined by the splendors of Renaissance architecture.

But during the eighteenth century, architecture came under siege. Its prestige was undermined conceptually.

What happened? As is well known among aestheticians, was the formation of what Paul Oskar Kristeller called "The Modern System of the Arts" 3 - also known as The Beaux Arts. This involved the segregation of poetry, drama, painting, sculpture, music and dance from the manual arts and crafts. However, this conceptual categorization or grouping required a rationale. What made portraiture a fine art whereas decorating saddles with paint was merely a craft? Several rationales or principles emerged. And none of them were favorable to the status of architecture as a fine art.

The first proposal, proffered by Abbé Batteux, was that something is a work of fine art only if it is an imitation of the beautiful in nature. ${ }^{4}$ This stipulation boded ill for architecture, since most architecture is not an imitation of anything. Some, of course, is, like the bird-shaped library of the University of Toronto. But this is a glaring exception.

Batteux's conception of the fine arts soon gave way to another due, in all probability, to the appearance and rise in influence of absolute or pure orchestral music. The symphonies of Haydn, Mozart, and Beethoven had to be accommodated conceptually. But their symphonies clearly were not really imitations of anything, least of all anything in nature.

The immediate solution to the problem was to subtract "imitation" from the criterion of "the imitation of the beautiful in nature." That left us with "the beautiful.” Thus, the fine arts were taken to be the arts of beauty - once again, The Beaux Arts.

But how to understand beauty?

Perhaps the most influential account was Kant's notion of free 
beauty or pure beauty in his Critique of the Power of Judgment. ${ }^{5}$ As is well known, this account amounted to the beauty being construed as the disinterested pleasure arising from the contemplation of forms of purposiveness without a purpose. Kant himself commented upon the consequence of this for architecture; he said that it could not afford an experience of pure beauty where such experiences were categorically divorced from purposes, including, with particular relevance to our discussion, moral purposes.

Subsequent commentators, undoubtedly misinterpreting Kant, took his account of free beauty as the defining ingredient of art, articulating this viewpoint in theories such as that of art-for-art's sake, of aestheticism, and eventually formalism. As a first approximation, these theories maintained that an artwork was something with the function of promoting experiences of free beauty. However, as it became obvious (as it already was to Kant), that that sort of beauty was too narrow a concept to cover the pertinent phenomena, the patent was extended under the label "aesthetic experience." On this new conception, an artwork is something with the function of promoting or affording aesthetic experience which, in turn, is generally understood as an experience valued for its own sake and not for the sake of anything else - that is, not for its utilitarian, moral, political, religious, social or otherwise putatively extrinsic purposes.

If it is true that the ascendency of absolute music forced this theoretical realignment, then perhaps that explains Walter Pater's famous assertion that "All art constantly aspires to the condition of music," where the music in question is pure music.

On this view of fine art, architecture could only be admitted into the circle of the muses in virtue of venustas - its appearance. Hence Venturi defined architecture-as-an-art as "a decorated shed." 6 Architecture was to be prized in terms of its formal properties, like "harmony" à la Corbusier. This approach to architectureas-an-art was probably already abroad in the early nineteenth century, as witnessed by Goethe who maintained alternatively that "Architecture is music become stone" or that "Architecture is frozen music."

By the mid-twentieth century, some of the more extravagant claims of aestheticism were tempered by what we can call the aesthetic theory of art which, on Monroe Beardsley's version of it, maintains that something is an artwork just in case it is made with the primary intention of affording some magnitude of aesthetic experience where aesthetic experience is still thought to exclude utilitarian purposes, moral purposes, cognitive purposes and so on. 
Although Beardsley parts company with formalists like Clive Bell, he still claims that art is an autonomous realm of practice, one whose function is the affordance of aesthetic experience which, again, is defined as distinct from the kinds of experiences promoted by other practices such as religion, politics, sports, philosophy and morality.

Anticipating somewhat and perhaps needless to say, the very notion of artistic autonomy ill suits an irreducibly heteronomous practice like architecture.

Artistic autonomism comes in two forms: radical autonomism and moderate autonomism. Radical autonomism claims that artworks properly so-called have nothing whatsoever to do with anything other than the promotion of aesthetic experiences. However, radical autonomism is too radical. Most of what is historically regarded as art, such as religious art, had purposes other than the promotion of aesthetic experience, even if it is conceded that the promotion of aesthetic experience was among its various purposes.

Alternatively, a moderate autonomist like Beardsley hedged his definition of art, requiring that artworks merely permit the affordance of aesthetic experience as a primary motivating intention. This allows that the work may have been made with other intentions, including religious ones. This sort of allowance gives rise to one version of what we can call moderate autonomism. On this view, artworks may have properties other than aesthetic properties - i.e., properties that give rise to aesthetic experiences - but the aesthetic dimension of the putative artwork is always categorically discreet from the other dimensions of the artwork, whether they be utilitarian, moral, religious, political, cognitive, and so forth.

Operationally this is taken to entail that, for example, a moral defect in an artwork is never an aesthetic defect nor does a moral virtue in an artwork ever add to the aesthetic quality of the artwork, properly so-called.

To see how this applies to a para-architectural artwork, recall the ancient story of the Brazen Bull of the tyrant Phalaris of Akragas, Sicily. Phalaris is reputed to have had constructed a Bronze Bull in which he had criminals executed. In effect, the bull was a giant pressure cooker in which the miscreants were roasted over an intense but slow burning fire. Supposedly the brazier was so constructed that the moans and screams of the immolating prisoners were transformed into allegedly beautiful harmonies by the apertures in the structure. Listeners were beguiled by the sonorous sounds emitted by the Brazen Bull. Nor, allegedly, were the sounds 
experienced as any less dulcet when the listeners learnt how the sounds were produced - which by anyone's understanding should be regarded as a form of cruel and unusual punishment. And, I suppose that even Phalaris would agree to this. After all that is what he designed it to be.

The moderate autonomist would concur that the Brazen Bull is an atrocity - a brutal torture chamber - and, to that extent, that it can be charged legitimately with moral defectiveness. But nevertheless, that moral defectiveness, the moderate autonomist argues, does not accrue any aesthetic demerits. The bull is bad, but beautiful. The moral judgment of it and the aesthetic judgment of it are necessarily, categorically twain. The artwork as an engine of moral retribution is evil and can be condemned as such. But the artwork-qua-art - in terms of moderate autonomism as parsed by the lights of the aesthetic theory of art - is a success, an artistic success.

Returning to Venturi's notion that architecture is a decorated shed, the "shed" half of the formula pertains to realizing all the functions of architecture that are not aesthetic - i.e., not devoted to affording aesthetic experience. The adjective "decorated" can be read as an abbreviation for the affordance of aesthetic experience. A structure is only a case of fine art in virtue of the latter. And it is only valuable qua architectural art insofar as it is decorated. If it has defects as a shed - if the roof leaks as do many of Frank Lloyd Wright's buildings - that does not count as an aesthetic defect - as a defect qua artwork - because from the perspective of moderate autonomism, a utilitarian defect never counts as an art-architectural defect.

Of course, moderate autonomism is not only concerned to insulate the artwork from charges of utilitarian defectiveness. From our point of view, we are particularly interested in its claim to insulate the architectural artwork qua artwork from criticism that would count a moral defect in the artwork as an artistic defect.

So the issue at hand is whether moderate autonomism is true with respect to architecture. This is at least the claim that: with respect to architecture-as-an-art, a moral defect will never count as an art-architectural defect (where for current purposes, an artistic defect is to be understood in terms of the aesthetic theory of art).

Against moderate autonomism with respect to architectural art, I wish to promote moderate moralism ${ }^{7}$ which, against moderate autonomism's "never," maintains that sometimes a moral defect in an artwork, including a work of architectural art, will count as an artistic defect, even understood in terms of the aesthetic theory of art.

My form of moralism is moderate insofar as it only holds that this is sometimes the case and not always the case. ${ }^{8}$ But if it is 
sometimes the case, that should be sufficient to defeat moderate autonomism, which claims that it is never the case.

The argument for moderate moralism begins by noting that artworks have functions or purposes including promoting aesthetic experiences, but not only that. Furthermore, it is the task of the artist to articulate or embody or implement those purposes in a manner or form that facilitates those purposes or that is adequate to or suitable or appropriate to those purposes. That is what artistry ideally amounts to - choosing the ways in which, from an array of options, the goals of the artwork are realized most adequately.

In other words, the artist is committed to finding the form suited to the purpose of the work. The form, on this view, is the selection of choices intended to realize the purpose or purposes of the work. Form here should be conceived in the model of the human form - the form of the work is the way or ways in which the purpose or purposes of the work are embodied.

Furthermore, artworks, including architectural artworks, can have among their purposes engendering emotional responses. For example, with respect to architectural artworks, typically Catholic cathedrals aim at eliciting awe by means of their vast, vaulting inner spaces.

Moreover, many emotions have a moral component as anger requires the belief that an injustice has been perpetrated against me or mine or as pity requires that the victim of misfortune be perceived to be undeserving.

Thus, attempting to engender a certain emotional response to an artwork may involve securing a contributory moral appraisal, or, at least, not provoking a moral appraisal contrary to the intended emotional response.

For example, as Aristotle points out, for the tragic emotion to take hold, the audience must not take the protagonist's suffering to be blameworthy, that is, a result of his moral defectiveness. In other words, the tragic character has to be designed in a certain way that is appropriate to the purpose of arousing the tragic emotion.

Seen this way, the character is one of the design elements of a tragedy - he/she is constructed from an array of choices in such a way that the final selection is ideally suited to achieving the purpose of the tragedy, namely, engendering pity and fear. Thus, the design of the character is a formal choice - a choice of the way the purpose of the work is to be embodied or articulated. Moreover, the character's design will need to possess certain moral elements if the character is to function properly and, in addition, it must not involve countervailing moral attributes. 
But if this is correct, it opens the possibility that a formal feature of a work may be defective as an artistic choice, because it is morally defective.

For example, the choice of an evil tyrant like Phalaris as the subject of a tragedy in which he is destroyed because of some morally blameworthy act of his own - perhaps he slips into the Brazen Bull and is burnt alive, while trying to push Mother Teresa into the blistering cauldron - would emotionally block the tragic response of pity and instead probably raise joy in our hearts due to the thought that justice had been served. But in any event, such a choice would defeat the emotional purpose of tragedy, rendering the form of the work defective, in consequence of its moral blemish, and, therefore, unable to deliver the intended aesthetic experience.

Given the conception of form as the choices that embody the purposes of a work, the choice of Phalaris, as he is typically portrayed, as a tragic protagonist would be a formal defect where form is a paradigmatic object of aesthetic experience. But it is also a moral defect involving a defective moral judgment on the part of the author in supposing that a catastrophe befalling a moral monster like Phalaris in the course of an evil act could be an appropriate object of pity. Thus, it is a defective formal choice inasmuch as it involves a defective moral judgment as a constitutive element, one that the audience is invited to share, but which it resists. And this formal/moral feature of the imagined work blocks the possibility of its affording an aesthetic experience of its form.

My point here, which is often overlooked, is that designing certain artworks requires making moral judgments and when those judgments are defective, the design-qua-design is flawed and, to that extent, undermined as an object of aesthetic experience.

Thus, in the case of Phalaris: The Tragedy, a moral defect in an artwork is a formal defect; an ethical flaw is an aesthetic flaw; a moral demerit counts as an aesthetic demerit. Therefore, moderate autonomism is false.

Now, the argument so far - and the thought experiment marshaled to support them - involves a narrative representation with characters. Can anything like it be mount for a non-narrative artwork, such as a work of architectural art? I think that the answer is "yes," just because architectural artworks, like narrative artworks, can be predicated upon the goal of engendering emotions, as in the case of Catholic cathedrals that are intended to provoke awe in the parishioners.

So in honor of the United States presidential election of 2016, let us imagine that Donald Trump won the election. Taking aim at 
his love of gold, humorists already have imagined that his first order of business would be to have the White House gold plated. Let us go them one better. Let us imagine that once he is elected, President Trump decides to build a new presidential residence, a veritable palace, a golden palace.

Putatively, the purpose of this palace is to elicit admiration.

As typically understood, this sort of admiration should be free of moral blemish. However, it seems to me that many will be unable to admire Trump's golden palace just because it would involve waste. Some may bridle at its vulgarity. But far more, I conjecture, will be disgusted, morally disgusted, by its excessive wastefulness. Moreover, moral disgust will defeat the aim of engendering admiration. Admiration here fails to be secured because the formal choice of articulating its appeal by means of tons and tons of gold is a morally inappropriate way to engender the pertinent sort of admiration, indeed, it is a way of generally canceling the probability of that response by arousing audience resistance to it. Thus, this case will have the same consequences for moderate autonomism as the case of Phalaris: The Tragedy.

It is important to see the difference between the case of Trump's golden palace and the seemingly comparable one where a new building is criticized morally because it has too large a carbon footprint. Presumably in the latter case, this criticism raises no aesthetic complications because the carbon footprint is not part of the artistic address of the building. But in the case of Trump's presidential palace, the choice of gold is part of the emotional address. That is, unlike having a large carbon footprint, the choice of gold is an integral part of the artistic design of the work. Thus, due to its moral significance, it compromises the aesthetic address of the palace qua artwork in a way that a large carbon footprint would not, even though it may independently raise ethical hackles.

One objection to my extension of the argument for moderate moralism from the narrative arts to architecture is that it would not have traction in a possible world slightly different from our own where gold is far more plentiful and where Trump's presidential palace would not constitute waste. However, I maintain that moral argument must be constrained by the world as we find it. The case against murder could not be made in a world where humans were invulnerable. Moreover, if the world were different and gold was widely abundant, our imagined President Trump would not have chosen it as a way of commanding admiration.

Another objection is that the gold in question as a formal dimension of the palace and its moral valence are distinct. This strikes 
me as false once we notice that it is a formal property of the palace because of its intended contribution to achieving the palace's aim of currying admiration, where that emotional aim requires that the gold as a formal choice not be undermined by its negative moral valence. Where an emotion like admiration is involved, moral value will be constitutive of the adequacy (or the lack thereof) of the formal choice. 9

To make a formal choice in the context of designing a work to elicit certain emotional responses frequently requires making a moral judgment about the ethical appropriateness of the choice and, if the moral judgment is defective, the formal choice to which it contributes essentially will also be simultaneously defective. To claim otherwise without showing what is wrong about this argument in terms of moral address is to beg the question in favor of moderate autonomism and against moderate moralism. It is simply to assert the truth of moderate autonomism, whereas I maintain that the kind of argument that I have just offered, which has been called the "uptake argument," shifts the burden of proof to the moderate autonomists not only with regard to the narrative arts but with regard to architecture as well.

My strategy so far has been to accept the terms of engagement of the moderate autonomist and to meet the challenge of showing how a moral defect could count as a formal defect in order to demonstrate that there is a connection between ethics, on the one hand, and the aesthetics and art of architecture, on the other hand. I think that the uptake argument can illustrate how this can be done.

But in addition I think that the connection along some dimensions between the aesthetics and ethics can be grounded easily within certain familiar conceptions of architecture. As mentioned earlier, Vitruvius maintained that architecture has three dimensions: firmitas (materiality), utilitas (function) and venustas (beauty - or, in more contemporary language, appearance or form). On the argument for moderate moralism that I have just offered, one of the functions of architecture is to elicit certain emotions, and the form or appearance of the building can be an indispensable means to achieving those ends. Sometimes moral considerations will figure in the success or failure of engaging the intended emotions. Consequently, sometimes moral considerations play a role in evaluating the achievement of architecture qua architecture in Vitruvian terms. ${ }^{10}$

One alternative view of architecture might be Venturi's - that architecture is a decorated shed. The "shed" here signals that architecture has materiality and serves a function. "Decoration" 
is treated as an independent component. This understanding implies that what is distinctive of the work of architecture - that is, that which distinguishes architecture from mere building - is decoration, understood as visual artistry, either as in the case of John Ruskin who thought of the work of architecture as the decoration of the surface of the structure, or, as in the work of various contemporary architects, like Frank Gehry, who by the grace of computer design, create buildings that are veritable visual spectacles, sometimes referred to as bordering on sculpture.

However, if architecture as art is conceived of as simply the visual aspect of architecture, one worries that this might involve committing what aestheticians of the natural environment, like Allen Carlson, think of as the "pictorial fallacy" - the mistake of treating a landscape as if it were a landscape painting.

If the art of architecture were essentially visual art, the work of the architect would be complete once she produces a sufficiently interesting architectural drawing. But such a conception of the art of architecture is nothing short of a reductio ad absurdam if taken as the standard view of what the art of architecture is.

On the standard view of architecture, the material, functional, and formal dimensions of building must be integrated; they must work together in concert and mutually constrain each other. And this entails that sometimes in pursuit of certain purposes, especially ones pertaining to emotional address, the form of the architectural artwork, as an object of aesthetic attention, will be constrained constitutively by morality. Or to put it in a Vitruvian idiom: where the function of a work of architectural art is to elicit certain emotional responses, the appearance or form of the work needs to serve the function in a morally appropriate or suitable way. ${ }^{11}$ 
1. Vitruvius, Ten Books on Architecture, ed. Ingrid Rowland (Cambridge: Cambridge University Press, 1999).

2. Ibid.

3. Paul Oskar Kristeller, "The Modern System of the Arts," Journal of the History of Ideas 12 (1951): 496-527 and 13: 17-46.

4. Charles Batteux, The Fine Arts Reduced to a Single Principle, trans. James Young (Oxford: Oxford University Press, 2015).

5. Immanuel Kant, Critique of the Power of Judgment, trans. Paul Guyer and Eric Matthews (Cambridge: Cambridge University Press, 2000).

6. Robert Venturi, Complexity and Contradiction in Architecture (New York: Museum of Modern Art, 1977).

7. See Noël Carroll, "Moderate Moralism," British Journal of Aesthetics 36 (1996): 223-238.

8. For an alternative version of moderate moralism, see Christian Baumberger. "The Ethical Criticism of Architecture: In Defense of Moderate Moralism," Architecture Philosophy 1 (2015): 179-197.

9. Sheila Lintott has made the observation that my examples in this article - The Brazen Bull and the golden palace-are both involved with causing harm: torture, on the one hand, and waste, on the other. But it is important to see that the argument need not rest solely on examples involving harm. See the example of the memorial in my article "Architecture and Ethics: Autonomy, Ethics, Art" in Architecture Philosophy 1 (2015): 139-156.

10. For an alternative view of how to connect Vitruvius' theory of architecture by considering his four features of architecture to be necessarily, indissolubly fused, see The Birth of Ethics from the Spirit of Tectonics by Stefan Koller (Delft: Technical University of Delft, 2015).

11. In this essay, among others, I have deployed moderate moralism to defeat autonomism. This position is meant as an argument designed to challenge the most reasonable case for autonomism, namely, moderate autonomism. It is not a general theory of the relation of aesthetics and ethics. I allow that there may be more connections than the one presented by the moderate moralist. That remains a topic for future research. Moderate moralism might be considered the "thin edge of the wedge" for that broader project. It attempts to demonstrate that there is one connection between aesthetics and ethics, thereby opening up the possibility that more may be discovered anon, i.e., there may be life beyond the uptake argument. 